\title{
DEBATE SOBRE EL MODELO ORGANIZATIVO ACADÉMICO Del modelo gremial al modelo colaborativo
}

\author{
DEBATE ON THE ACADEMIC ORGANIZATION MODEL \\ From the guild to the collaborative model
}

\author{
SUSANA PASAMAR spasrey@upo.es \\ Universidad Pablo de Olavide. Sevilla.
}

La difícil situación económica, el incierto futuro de la investigación y la educación, o la escasa relación de la universidad con la sociedad y el mundo empresarial no han hecho sino acrecentar la necesidad de un debate en profundidad sobre el futuro del sistema universitario público. El modelo organizativo universitario se ha situado en el punto de mira, y aunque parece que existe cierto consenso en la necesidad de acometer cambios, no parece clara qué dirección y profundidad deberían tener dichos cambios.

En este contexto, la oportunidad del artículo de Heckscher y Martín-Ríos es clara. El propósito de su ensayo es en definitiva generar un debate sobre la transición del presente modelo organizativo universitario de carácter gremial a otro de carácter burocrático, en el que se supere la ineficacia e ineficiencia que se achaca a la estructura tradicional académica. Heckscher y Martín-Ríos plantean una alternativa a ambos modelos, buscando soluciones que salven las numerosas disfunciones de los modelos estandarizados y proponiendo el modelo de universidades colaborativas.

La crisis del modelo gremial clásico refuerza la necesidad de una profunda reorganización de las universidades. Las universidades como centros de generación y transmisión de conocimiento se presentan con estructuras herederas de las universitas magistrorum con origen en el s. XII, en las que el gremio se reservaba el derecho de admisión y aprobación de los aprendices, manteniendo formas de autorregulación e independencia.

La desconexión de la universidad en su modelo más tradicional con las demandas sociales y empresariales, y una búsqueda de mayor eficiencia y eficacia llevan al planteamiento de estructuras burocráticas como alternativas de gestión. Sin embargo, estas estructuras funcionales en las que se incide en la normalización de los procesos de trabajo y en el control de las prácticas académicas no son adecuadas para entornos complejos. La excesiva centralización o la excesiva formalización pueden llevarnos a errores frecuentes como algunos de los mencionados por Heckscher y Martín-Ríos, "a expensas de la innovación y la capacidad de reacción". En muchos casos las universidades públicas españolas están más centradas en cumplir objetivos inmediatos fijados por la Agencia Nacional de Certificación Académica que en incrementar sus niveles de cali- 
dad docente e investigadora a medio y largo plazo. Si centramos el debate en el profesorado, no es difícil encontrar académicos más preocupados en publicar en determinadas revistas, que en la calidad real de su investigación, y mucho menos de la docencia. De las críticas a las que daban pie los sistemas establecidos en la Ley de Autonomía Universitaria (LAU) o la Ley de Reforma Universitaria (LRU), o las desventajas del sistema de habilitación, hemos pasado a la existencia de agencias estatales y autonómicas, a las que los candidatos a promoción presentan su currículo en procesos que cuanto menos, no son claros.

Actualmente a los profesores universitarios se nos exige dedicación docente, resultados de investigación, e incluso participación en la gestión académica. Si analizamos estas tres actividades, curiosamente los profesores universitarios somos los únicos docentes que no tenemos que acreditar una formación relativa a la docencia. Tal y como el profesor Zabalza señala, se han asentado ciertas ideas confusas y peligrosas, como que para ser buen docente basta con ser buen investigador, o que la calidad de una universidad no depende tanto de la docencia sino de contar con recursos como tecnologías, laboratorios... Pero aún es más, si el modelo investigador se orienta a una generación de resultados a corto plazo, y a cumplir criterios de agencias de evaluación más que a la transmisión del conocimiento generado, podemos encontrarnos con universidades públicas muy bien situadas en los nuevos rankings de investigación, pero con una mala calidad docente y con una investigación que no sale de los circuitos académicos. Así Heckscher y Martín-Ríos apuntan lo que efectivamente parece desproporcionado, como es la generación de 5.000 artículos sobre Shakespeare como un síntoma del problema. Pero mi preocupación va más allá. No digamos ya los 5.000 artículos, pero ¿cuántos de esos artículos han sido leídos fuera del ámbito universitario? El sistema ha generado una preocupación no ya por la divulgación de los resultados de la investigación, si no una atención casi exclusivamente orientada a las revistas en las que se debe publicar.

Quizás no deberíamos obviar el modelo de burocracia profesional, que Heckscher y Martín-Ríos no incluyen en el debate. Esta configuración es apropiada para entornos complejos e incorpora elementos como la autonomía, descentralización y el ambiente democrático, que por otra parte conllevarían una mayor motivación y responsabilidad del profesorado. Los académicos cuentan con altos niveles de preparación y un considerable grado de autocontrol sobre su trabajo. Este modelo organizativo, que en teoría es al que aspira el actual sistema universitario, incorporaría los elementos positivos de los sistemas burocráticos pero entendiendo la singularidad del trabajo realizado por los profesores académicos. Una burocracia de corte más mecanicista efectivamente no tendría sentido en un entorno como el actual, en el que se exige a la universidad que se adecue a los cambios del entorno, incrementando su competitividad y mejorando su capacidad de respuesta a las demandas sociales. El problema en este tipo de configuraciones puede ser el control, que puede recaer en instituciones externas a la propia organización. Pero el actual enfoque excesivo en el control de resultados que ya hemos mencionado está haciendo virar el sistema de la burocracia profesional a casi una burocracia 
de corte mecanicista, corriendo el riesgo de convertirse en un modelo inflexible. Y quizás es ahí donde la incorporación de elementos de corte colaborativo tendría más sentido.

Heckscher y Martín-Ríos proponen el modelo colaborativo que ha funcionado con éxito en organizaciones como IBM, basado en el establecimiento de un propósito común y la creación de equipos de trabajo interdisciplinares. Desde el punto de vista teórico este esquema parece el más favorable para la producción e intercambio de conocimiento, pero aunque los autores confían en los resultados positivos derivados de esta alternativa, no aportan evidencias claras extrapolables fácilmente al mundo universitario. Sin embargo, sí destacan algunos de los obstáculos que supondría un viraje a una estructura organizativa colaborativa. ¿Es factible implantar un modelo colaborativo en una universidad como la nuestra? ¿Cuál es el ámbito de la colaboración: el conjunto de universidades públicas, cada una de las universidades...? ¿Estamos los académicos dispuestos a involucrar a colectivos interesados en nuestras decisiones? ¿Pero quiénes son exactamente nuestros grupos de interés? ¿Alumnos, empresas, autoridades gubernamentales de diferente nivel...? ¿Y cómo incluir a todas las disciplinas en este diálogo?

El modelo no deja de ser interesante, y probablemente se pueden incluir rasgos de la estructura colaborativa en el modelo universitario. Pero el modelo colaborativo en el mundo empresarial es aún una excepción, y no queda claro que sea aplicable en su totalidad al mundo académico. El debate está abierto.

\section{REFERENCIAS BIBLIOGRÁFICAS}

Heckscher, C., \& Martin-Rios, C. (2013). "Looking Back, Moving Forward: Toward Collaborative Universities". Journal of Management Inquiry, 22, 1, 136-139.

Zabalza, M.A. (2009). "Ser profesor Universitario hoy." La cuestión universitaria, 5: 69-81.

Susana Pasamar es Profesora del Departamento de Organización de Empresas y Marketing de la Universidad Pablo de Olavide, Sevilla, imparte docencia en asignaturas de Recursos Humanos y Economía de la Empresa en diferentes titulaciones de grado y postgrado. Actualmente sus líneas de investigación están relacionadas con la conciliación de la vida profesional y personal y el aprendizaje organizativo ambidiestro. 